\title{
Providing Lifestyle Counseling to Cancer Patients during Routine Consultation: Instrument Development and Reliability
}

\author{
Obiageli Crystal Oluka ${ }^{1}$, Rachael Apio ${ }^{2}$, Phelire Phiri ${ }^{1}$, Shaofa Nie $^{1}$, Yi Sun $^{2 *}$ \\ 1. Department of Epidemiology and Health Statistics, Tongji Medical College, Huazhong University of \\ Science and Technology, 13 Hangkong Road, 430030, Wuhan, Hubei, China; \\ 2. Department of Social Medicine and Health Management, Tongji Medical College, Huazhong \\ University of Science and Technology, 13 Hangkong Road, 430030, Wuhan, Hubei, China
}

\begin{abstract}
Lifestyle factors are widely being implicated in the prognosis and recurrent development of many cancers. As the incidence of various cancers is rapidly increasing in Nigeria, with limited and expensive treatment options; lifestyle changes have been proposed to help curb the disease. The aim of this study is to elicit the salient behavioral, normative and control beliefs of Nigerian doctors regarding providing lifestyle counseling to cancer patients and developing a valid and reliable questionnaire to this effect based on the Theory of Planned Behavior.

Three phases of the theory are described including; belief elicitation, questionnaire development and pilot study. The elicitation study identified the salient modal beliefs underlying Nigerian doctor's motivations to provide lifestyle counseling. A questionnaire was constructed incorporating all the key theoretical constructs of TPB, content validated by three experts and piloted on a sample of 30 doctors for internal consistency and temporal stability analysis. The questionnaire proved to be reliable with Cronbach's alpha coefficients of $>0.7$ and significant Intraclass correlation coefficient was observed for most variables.

The study shed light on the beliefs of Nigerian doctors on providing lifestyle counseling and the instrument developed demonstrated acceptable evidence of content validity and reliability.
\end{abstract}

Keywords: Cancer; cancer treatment/management; lifestyle factors; theory of planned behavior; instrument development

\section{Introduction}

Cancer, one of the most dreaded chronic diseases worldwide is fast gaining momentum in Nigeria. The incidence and mortality statistics are outrageous and are unlikely to improve in the near future unless drastic measures are undertaken. The fact that there is currently no National cancer policy in the country paints a picture of the uphill task awaiting the country in combating and controlling the disease.

Several studies have identified the different challenges the Nigerian cancer care system has to tackle to effectively control the disease burden. ${ }^{1,2,3,4}$ Limited number of qualified manpower especially oncology specialists as well as lack of finances are some of the challenges identified. Various cost-effective strategies have been proposed to tackle these issues but due to the continued and glaring absence of a National cancer policy in the country; none is yet to be implemented. One of such proposed strategies is the recruitment of primary care doctors, regardless of their specialties, to provide lifestyle counseling to cancer patients/survivors that are tailored to their individual needs and abilities. ${ }^{6}$ Of particular interest are the areas of; diet, physical activity and weight management. These factors have been increasingly implicated in the development and prognosis of many cancers. ${ }^{6,7,8}$

The Theory of Planned Behavior (TPB) is a model of behavior change which has demonstrated its effectiveness in many health behavior studies including those involving physicians and other health professionals. ${ }^{9,10,11}$ The theory works on the assumption that the behavior of a person is dependent on intention, which in turn is a function of three main independent variables: attitude towards the behavior, subjective norm (SN- perceived social pressure to/ not to perform the behavior) and perceived behavioral control (PBC- factors that encourage or discourage performance of the behavior). No previous studies investigating the predictors of doctors' adoption of lifestyle counseling to cancer patients, based on TPB, were found hence, no questionnaires exist to that effect.

This qualitative study is aimed at eliciting the salient behavioral, normative and control beliefs of Nigerian doctors regarding providing lifestyle counseling (on diet, exercise and weight) to cancer patients and developing a valid and reliable questionnaire to this effect based on TPB.

For the purpose of this study, the term "Doctor" is used to refer to participants who are trained and licensed to treat sick and injured people regardless of their area of specialty. 


\section{Methods}

\section{Phase 1: Elicitation of Beliefs}

The population of interest (Doctors) and behavior under study (lifestyle counseling) were carefully defined using the TACT principle as follows: providing lifestyle counseling (Action) to cancer patients/survivors (Target) during routine consultation (Time) in Nigerian hospitals and health centers (Context). This is to ensure that all the TPB measures included, are specified at the same level of generality. ${ }^{12,13}$ An elicitation study to identify the salient behavioral, normative and control beliefs of doctor's concerning the behavior of interest was conducted using self-administered open-ended questionnaires. The beliefs garnered will be used as a basis for the construction of indirect measures of the TPB independent variables (Attitude, Subjective norm and Perceived Behavioral Control).

Two main government general hospitals in Enugu state (University of Nigeria Teaching hospitalUNTH and Enugu State University of Science and Technology Teaching Hospital- ESUTH); one of the main cities in Southeastern Nigeria were selected for the study. Ethical approval and permission was obtained from the Ethics Review Board of Tongji Medical College, Wuhan, China and also from that of UNTH and ESUTH, Enugu. Only certified primary care doctors with at least one year of experience were eligible to participate. Participants were informed about the aims of the study and assured of anonymity and confidentiality. Written consent was obtained from all participants.

Self-administered open-ended questionnaires were presented to participants as advocated by the relevant methodology. ${ }^{12}$ The questionnaire (Table 1) explored general and specific aspects of providing lifestyle counseling and also included a brief demographic section.

Two researchers independently content analyzed the responses into themes (behavioral, normative and control beliefs), listing them from most frequently to least frequently mentioned as recommended by Francis et al. $^{12}$

Table 1 Open-ended questions for the elicitation study

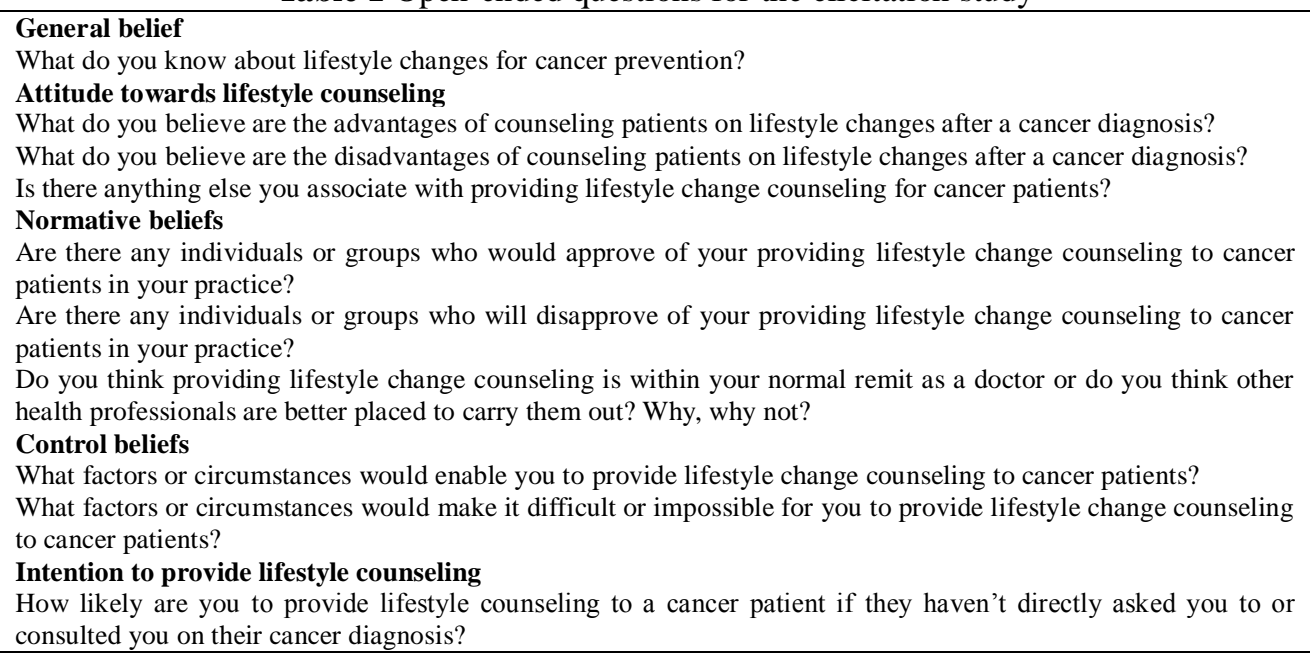

\section{Results}

15 doctors, selected from the two teaching hospitals, participated in the study. In total, 9 of these participants were female and 6 were male. The demographic data are presented in Table 2.

Most doctors claimed to be knowledgeable regarding lifestyle changes for cancer prevention with majority of participants attributing these changes to quitting smoking. A few others mentioned diet and alcohol consumption as being instrumental in cancer prevention. Some others attributed it to avoiding occupational hazards, exercising and going for routine tests such as; pap-smear for cervical cancer.

\section{Behavioral beliefs}

Decreased rate of cancer growth/progression and improved prognosis are the main advantages of providing lifestyle counseling to cancer patients as defined by participating doctors. These outcomes were mostly attributed to smoking.

"Quitting smoking will decrease the growth of the cancer and improve prognosis and management"

A few others considered routine screening tests such as Prostate-Specific Antigen (PSA) test, as being advantageous to the prognosis of cancer.

"Going for screening tests like mammograms and PSA testing at least once a year will improve prognosis of cancer"

Other positive outcomes mentioned include: decreased mortality; improved quality of life \& chances of 
survival; decreased risk of co-morbidities like diabetes and heart disease.

Most doctors $(60 \%)$ reported no disadvantages. Others highlighted some key disadvantages including: depression; difficulty accepting/adjusting/adhering to lifestyle changes; absconding from treatment.

"The patients will become depressed if I tell them to change their lifestyle"

"Most patients will not be able to accept or adjust to new changes in their lifestyle"

"I don't think the patients will agree to change their lifestyle in fact, many of them will abscond"

Other views expressed with respect to lifestyle counseling include: the need for provision of other treatment options; counseling will grant knowledge and awareness to patients; need to consider the cultural beliefs of each patient during counseling.

\section{Normative beliefs}

The United Nations (UN) and other international organizations and NGO's were the most important groups the doctors stated were likely to influence their decision to provide lifestyle counseling to cancer patients. It was believed that these organizations will also influence the Nigerian health authorities.

"If the UN recommends lifestyle counseling for cancer patients then I will provide it"

"Once it is recommended by international organizations and NGO's I will do it"

"If the UN, WHO and other organizations recommend it, health authorities will adopt it and I will do it"

Others stated that the opinion of their senior colleagues, oncologists, gynecologists and patients would be influential to their actions. One doctor stated that no one can influence his actions as one's practice is private in Nigeria.

"Practice is private and individuals and groups are unlikely to influence my practice"

The question "Do you think providing lifestyle counseling is within your normal remit as a doctor or do you think other health professionals are better placed to carry them out?" had 12 positive responses with only 3 doctors responding "No". Most felt that counseling cancer patients would be better handled by doctors than other health professionals.

\section{Control beliefs}

Factors that would encourage or make it difficult for them to provide lifestyle counseling were based mostly on factors pertaining to the patients and the doctors themselves. Commonly quoted patient-related factors include: severity of the disease/ stage of cancer; age of patient; socioeconomic status; religious beliefs; interest/cooperation from patients and family support.

"If the disease is in the late stage and very severe, I will not bother the patient with lifestyle changes"

"Patients who are poor cannot afford to pay for any lifestyle changes"

"If patients are cooperative and interested it will encourage me to counsel them"

Factors pertaining to the doctors include: time and workload, adequate personal knowledge and training, lack of other trained personnel.

"If there are no other health workers trained to provide counseling to them, I will do it"

"Most clinic days, patients are too many so I may not have time to provide lifestyle counseling"

Another factor that was mentioned is the lack of adequate facilities and limited health workers to support the counseling compounded by an excess in the number of patients.

\section{Intention}

One question (How likely are you to provide lifestyle counseling to a cancer patient if they haven't directly asked you to or consulted you on their cancer diagnosis?) was used to assess doctor's intention to provide lifestyle counseling. 9 respondents said they are likely to provide counseling, 5 said unlikely and one gave no response. Those who are likely to provide counseling agreed it is an important part of cancer management.

Table 2: Elicitation population characteristics

\begin{tabular}{lll}
\hline Characteristics & $\mathrm{n}(\%)$ & Mean (SD) \\
Gender & $6(40)$ & \\
Male & $9(60)$ & \\
Female & & \\
Place of Employment & $10(66.7)$ & \\
UNTH & $5(33.3)$ & \\
ESUTH & & \\
Specialty & $1(6.7)$ & \\
Oncology & $6(40)$ & $4.53(3.89)$ \\
General practice & $8(53.3)$ & $5.27(1.33)$ \\
Other & - & \\
Mean years qualified & - & \\
No of work days/week & & \\
\hline
\end{tabular}




\section{Measures}

\section{Phase 2: Questionnaire Development}

Salient beliefs representing each TPB construct were derived from the elicitation study as earlier described. Each TPB predictor variable was measured directly (by asking respondents about their overall beliefs) and indirectly (by asking for specific beliefs and the weight of each belief).

The direct measures included 2 attitude items, 2 items on SN, 3 items on PBC and 3 items on intention. The response format for all items was a 7-point Likert scale ranging from 1 (strongly disagree) to 7 (strongly agree) except for a few whose endpoints were recorded in reverse. Individual item scores were averaged to produce a composite score for each construct.

Indirect measures were based on 5 behavioral beliefs for attitude and their corresponding outcome evaluations (10 items in total); 5 normative beliefs for $\mathrm{SN}$ and their corresponding motivation to comply (10 items in total); and 2 control beliefs for PBC and their corresponding strength of belief (4 items in total). Therefore, participants were first required to indicate their specific beliefs based on the questionnaire items and secondly, indicate the extent to which these beliefs affect/ influence them. Scoring was either unipolar; 1 (extremely unlikely) to 7 (extremely likely) or bipolar; -3 (extremely undesirable) to 3 (extremely desirable). Each behavioral belief was multiplied by its corresponding outcome evaluation to produce a weighed score. Weighed scores of each normative/control belief and motivation to comply/strength of belief respectively, were also obtained likewise. These weighed beliefs were summed to create composite scores for attitude, SN and PBC.

For both direct and indirect measures, scores were coded or reversed so that items with negatively worded endpoints (e.g. strongly disagree) had lower numbers and positively worded items (e.g. extremely desirable) had higher numbers. This is so that high summary scores consistently reflect stronger or more positive beliefs towards the target behavior. ${ }^{12}$

An item on Behavioral outcome, assessed based on a Yes/No question (Do you provide lifestyle counseling to your patients diagnosed with cancer?) was also included as well as five demographic and background questions.

Quality appraisal of the questionnaire developed was conducted using a checklist developed by Oluka et al. ${ }^{14}$ to ensure minimal potential for bias.

\section{Content Validity}

For content validation, the instrument was submitted to three judges with knowledge and expertise on instrument development, validation and theoretical frameworks for health behavior research. They assessed the instrument based on its title, items, response format, scoring and length (to avoid participant fatigue and ensure high response rates). They also assessed the instrument on clarity to ensure items are easily understandable.

Issues on scoring for the indirect measures of attitude, subjective norm and perceived behavioral control was extensively debated and eventually resolved that it be based on whether the concepts to be measured are unidirectional or bidirectional such that unidirectional items (e.g. behavioral belief) be treated as probabilities and measured using unipolar scales (1-7) while bidirectional items (e.g. control belief strength) be measured using bipolar scales $(-3$ to +3$) .{ }^{12}$ They also agreed that items measuring different constructs be mixed up so as to reduce repetition of responses as recommended by Ajzen. ${ }^{15}$

Items with $100 \%$ agreement between judges were left unchanged and those with disagreement were discussed until a consensus was reached. A copy of the final instrument is attached as a supplementary file.

\section{Phase 3: Pilot Study}

The objective of the pilot was to further identify any issues regarding the layout and content of the questionnaire items as well as assess their content validity and reliability.

\section{Procedure}

Thirty doctors' working at UNTH and ESUTH were recruited for the pilot study between January and February, 2014. 17 of the participants worked at UNTH while 13 worked at ESUTH. The questionnaire was self-administered and took approximately $20 \mathrm{~min}$ to complete. Each questionnaire was identified by a unique identification number. An informed consent form was attached to each questionnaire and participants were assured of confidentiality. 10 of the initial participants were approached two weeks later to complete the questionnaire a second time so as to assess the agreement between answers at both times based on the temporal stability criterion. ${ }^{16,17}$

The questionnaire was divided into two sections with the first section based on demographic questions and the second based on the key TPB constructs earlier discussed.

Data was entered into SPSS 20 and analyzed for internal reliability. Cronbach's alpha was first used to calculate the content reliability of the TPB direct measures, excluding the indirect measures which are not 
expected to be internally consistent due to the ambivalence of people's attitude, SN and PBC toward a behavior. ${ }^{15}$ Then, we assessed temporal stability (test-retest reliability); another method of estimating reliability, using Intraclass correlation coefficient (ICC). This method is recommended for both direct and indirect measures with an added advantage of it attempting to predict future behavior. ${ }^{15}$

\section{Results}

Questionnaires from both the first $(n=30)$ and second $(n=10)$ phase of the pilot recorded a 100\% response rate. Only 10 participants were included in the test-retest phase of the study so as to obtain at least $30 \%$ of our initial sample as recommended in previous TPB studies. ${ }^{17,18}$

Demographic characteristics of the study population was calculated and presented in Table 3. More than $50 \%$ of the participants were male with only $2 \%$ of the entire population specialized in oncology. The question on past behavior of providing lifestyle counseling to cancer patients indicated an $80 \%$ positive response from participants.

Table 3: Characteristics of Pilot population $(n=30)$

\begin{tabular}{llll}
\hline Variables & $\mathrm{n}(\%)$ & Mean (SD) & Range \\
\hline Gender & & & \\
Male & $17(56.7)$ & & \\
Female & $13(43.3)$ & & \\
Employment & & & \\
UNTH & $17(56.7)$ & & \\
ESUTH & $13(43.3)$ & & \\
Specialty & & & \\
Oncology & $2(6.7)$ & & \\
GP & $8(26.7)$ & & \\
Other & $20(66.7)$ & & \\
No.work days/wk & - & $5.93(0.91)$ & \\
Years qualified & - & $5.03(2.74)$ & \\
Providecounseling & & & \\
Yes & $24(80)$ & & \\
No & $6(20)$ & & \\
\hline
\end{tabular}

\section{Content Reliability}

Analysis of instrument' directly measured items was conducted for content reliability using Cronbach's alpha as shown in Table 4. The constructs all had alpha coefficients $>0.7$ which is considered excellent. ${ }^{19,20,21}$

Table 4: Mean, SD and internal consistency of constructs $(n=30)$

\begin{tabular}{lllll}
\hline Construct & No. of items & Mean (SD) & Range & Cronbach's alpha \\
\hline Direct measures & & & & \\
Attitude & 2 & $6.87(0.32)$ & $6-7$ & 0.82 \\
SN & 2 & $5.98(1.23)$ & $2-7$ & 0.81 \\
PBC & 3 & $6.72(0.47)$ & $5-7$ & 0.84 \\
Intention & 3 & $5.49(1.00)$ & $2-7$ & 0.84 \\
Indirect measures & & & & - \\
Attitude & 10 & $64.77(16.78)$ & $23-91$ & - \\
SN & 10 & $43.93(24.14)$ & $-5-99$ & - \\
PBC & 4 & $19.27(10.76)$ & $0-39$ & \\
\hline
\end{tabular}

\section{Temporal Stability}

Answers from the first and second (test-retest reliability) questionnaires assessed for temporal stability were considered to be fair for values of ICC between 0.4 and 0.59 ; good for values between 0.6 and 0.74 ; and excellent for values higher than $0.75 .^{17,22,23}$ Table 5 shows the ICC result for each construct. Temporal stability was shown to be poor for PBC (direct measure), fair for intention and good for all other constructs except direct measure of attitude which was excellent.

Table 5: Test-retest stability of constructs $(n=10)$

\begin{tabular}{llll}
\hline Construct & ICC & $95 \% \mathrm{CI}$ & P-value \\
\hline Direct measures & & & 0.003 \\
Attitude & 0.75 & $0.29-0.93$ & 0.008 \\
SN & 0.68 & $0.16-0.91$ & 0.127 \\
PBC & 0.36 & $-0.28-0.79$ & 0.034 \\
Intention & 0.55 & $-0.05-0.86$ & 0.010 \\
Indirect measures & & & 0.019 \\
Attitude & 0.66 & $0.14-0.90$ & 0.006 \\
SN & 0.61 & $0.05-0.89$ & \\
PBC & 0.71 & $0.21-0.92$ & \\
\hline
\end{tabular}




\section{Discussion}

This study provided a detailed insight on the beliefs of Nigerian doctors concerning providing lifestyle counseling to patients diagnosed with cancer. Also, in accordance with the study aims, a TPB-based questionnaire was developed and piloted for subsequent use in a large-scale survey. The questionnaire proved to be content valid and reliable after undergoing a preliminary analysis, with only minor changes in format and wording required.

To the best of our knowledge, this is the first study aimed at assessing Nigerian doctors' intention to provide lifestyle counseling to patients diagnosed with cancer, during routine consultation. Science has evolved to the point that interventions require a strong evidence base before they can be approved for take-off. The TPB, a widely recognized framework for the study of human behavior, requiring a detailed and rigorous process has been employed in this study. ${ }^{24}$ Proper operationalization of the theory is necessary to achieve valid and reliable results with the potential to shape behavior change interventions. ${ }^{25}$

In the belief elicitation phase, while participants seemed adequately knowledgeable about lifestyle factors and its influence on cancer, most of them commented that lifestyle changes are only beneficial before a cancer diagnosis and will be of little/no effect once one is diagnosed with the disease. This suggests that it might be necessary to consider training Nigerian doctors on the effects of lifestyle changes on cancer survival, so as to achieve adequate effectiveness of future interventions.

There are stringent procedures for the development of a valid and reliable TPB-based questionnaire. After the instrument had been developed based on responses from the belief elicitation, it was critically appraised for quality using the instrument developed by Oluka et al. ${ }^{14}$, a step deemed necessary to ensure minimum potential for bias. The questionnaire proved to have a low potential for bias and content validation also aided in drawing conclusions about the quality of the scale. Diverse views surrounding the operationalization of TPB were hashed out and a consensus was reached on which steps to adopt. Inclusion of both direct and indirect measures of the TPB constructs is one of such issues. It was resolved that neither approach is perfect and as recommended by Francis et al. ${ }^{12}$, both methods were included as scores are expected to be positively correlated when tapping the same construct.

As regards reliability, the results based on Cronbach's alpha indicate that the instrument constructs are internally consistent. Also for temporal stability, all measured constructs except for the direct measure of PBC, revealed stability in the interval examined, which is important for future interventions aimed at predicting the evolution of these perceptions. ${ }^{15,16,26}$

Although the aim of this study was to develop a valid and reliable questionnaire and not to generalize its findings, it is interesting to note that $80 \%$ of participants stated that they provide lifestyle counseling to cancer patients; an evidence to past behavior. The finding suggests a higher likelihood of these participants to declare an intention to provide lifestyle counseling compared to the $20 \%$ who had given a negative response to the behavior. This is worthy of investigation in a larger scale study as it begs to reason that positive past behavior may likely influence future behavior positively.

Some limitations in our study are worthy of note. The beliefs used to assess the TPB constructs in the questionnaire were based on an elicitation study of Nigerian doctors and not wholly from literature. Though this constitutes strength as the beliefs are likely to be valid in determining intention to provide lifestyle counseling, it may require a lot of modification when employing them in other non-similar populations. This study also used self-administered questionnaires during the elicitation phase as opposed to the commonly used focus group method hence; the information obtained may not be rich enough ${ }^{27}$ given the limited knowledge of participants on lifestyle counseling for cancer. Finally, the questionnaire included 40 questions which may result in participant fatigue or lowered motivation thereby impacting on data quality. ${ }^{12,17}$

Considering the dire circumstances of cancer care in Nigeria, the use of the instrument developed in this study on a larger population of doctors, may help detect which factors have the strongest influence on intention to provide lifestyle counseling to those diagnosed with cancer. Such a study will provide a strong evidence base for health policy-makers in Nigeria and may ultimately influence National cancer policy and practice in the country.

\section{Conclusion}

The instrument developed in this study to assess the factors influencing provision of lifestyle counseling for cancer patients, among Nigerian doctors, is a tool with valid contents and concepts with evidence of internal consistency. The instrument will be employed in a larger sample of doctors with the aim of designing a lifestyle counseling program for Nigerians and other similar populations diagnosed with cancer to help improve their chances of survival. 


\section{References}

[1]. Akinremi TO, Chidiebere NO, Ayodeji OO. Review of prostate cancer research in Nigeria. Infectious Agents and Cancer. 2011; 6(Suppl 2):S8.

[2]. Adebamowo C. Cancer Care in Nigeria Part 1: The Social Cost of Cancer. American Society of Clinical Oncology 2013.http://connection.asco.org/Commentary/Article/id/3594/Cancer-Care-in-Nigeria-Part-1-The-Social-Cost-of-Cancer.aspx (Commentary on ASCO Connection).

[3]. Eguzo K, Camazine B. Cancer Care in Resource-Limited Settings: A Call for Action. J Cancer SciTher 2012; 4: 223-226. doi:10.4172/1948-5956.1000145.

[4]. Adisa CA, Eleweke N, Alfred AA, Campbell M J, Sharma R, Nseyo O, Tandon V, Mukhtar R, Greninger A, Risi J D, Esserman L J. Biology of breast cancer in Nigerian women: A pilot study. Ann Afr Med 2012; 11:169-75.

[5]. Ugwu EO, Obi SN, Ezechukwu PC, Okafor II, Ugwu AO. Acceptability of Human Papilloma Virus Vaccine and cervical cancer screening among female healthcare workers in Enugu, Southeast Nigeria. Nigerian Journal of Clinical Practice 2013 ; vol 16: 2.

[6]. Oluka OC, Shi Y, Nie S, Sun Y. Boosting cancer survival in Nigeria: Self-management strategies. Asian Pac J Cancer Prev 2014a; 15 (1): 335-341.

[7]. Rock CL, Doyle C, Denmark-Wahnefried W, et al. Nutrition and Physical Activity Guidelines for Cancer Survivors. CA Cancer J Clin 2012;62: 242-274.

[8]. Davies NJ, Batehup L, Thomas R. The Role of Diet and Physical Activity in Breast, Colorectal and Prostate Cancer Survivorship: A review of Literature. British Journal of Cancer 2011; 105: S52-S73.

[9]. Wade J, Smith H, Hankins M, Llewellyn C. Conducting oral examinations for cancer in general practice: what are the barriers? Family Practice 2010; 27: 77-84.

[10]. Hagger MS, Chatzisarantis NLD, Biddle SJH. A meta-analytic review of the theories of reasoned action and planned behavior in physical activity: Predictive validity and the contribution of additional variables. J Sport ExercPsychol 2002; 24(1):3-32.

[11]. Hausenblas HA, Carron AV, Mack DE. Application of the theories of reasoned action and planned behavior to exercise behavior: A meta-analysis. J Sport ExercPsychol 1997; 19(1):36-51.

[12]. Francis JJ, Eccles MP, Johnston M et al. Constructing Questionnaires Based on the Theory of Planned Behavior: AManual for Health Services Researchers. Newcastle: Center for Health Services Research, 2004.

[13]. Fishbein M, Ajzen I: Belief, attitude, intention and behaviour: an introduction to theory and research London: Addison-Wesley; 1975 .

[14]. Oluka OC, Nie S, Sun Y. Assessment of TPB-Based Questionnaires: A Systematic Review. PLos ONE 2014b; 9(4): e94419. [doi:10.1371/journal.pone.0094419].

[15]. Ajzen I. Constructing a TpB Questionnaire: Conceptual and Methodological Considerations(2006). Available at: http://www.unibielefeld.de/ikg/zick/ajzen\%20construction\%20a\%20tpb\%20questionnaire.pdf Accessed: 25 August, 2014.

[16]. Cornélio ME, Gallani MCBJ, Godin G, Rodrigues RCM, Mendes RDR, Nadruz W Junior. Development and Reliability of an Instrument to Measure Psychosocial Determinants of Salt Consumption among Hypertensive Patients. Rev Latino-am Enfermagem 2009; 17(5):701-7.

[17]. Malo C,Neveu X, Archambault PM,Émond M, Gagnon M. Exploring Nurses' Intention to Use a Computerized Platform in the Resuscitation Unit: Development and Validation of a Questionnaire Based on the Theory of Planned Behavior. Interact J Med Res 2012; vol 1, issue 2, e5.

[18]. Gagné C, Godin G. Les théoriessocialescognitives: Guide pour la mesure des variables et le développement de questionnaire. SteFoy, QC: Groupe de recherchesur les aspects psychosociaux de la santé. École des sciences infirmières, Université Laval; 1999.

[19]. Mendez RDR, Rodrigues RCM, Cornelio ME, Gallani MCBJ, Godin G. Development of an instrument to measure psychosocial determinants of physical activity behavior among coronary heart disease patients. Rev Esc Enferm USP 2010; 44(3): 583-94.

[20]. DeVon HA, Block ME, Moyle-Wright P, Ernst DM, Hayden SJ, Lazzara DJ, et al. A psychometric toolbox for testing validity and reliability. J NursScholarsh 2007; 39(2):155-164. [doi: 10.1111/j.1547-5069.2007.00161.x] [Medline: 17535316]

[21]. Watson R, Thompson DR. Use of factor analysis in Journal of Advanced Nursing: literature review. J AdvNurs 2006; 55(3):330341. [doi: 10.1111/j.1365-2648.2006.03915.x] [Medline: 16866827]

[22]. Rosner B. Fundamentals of Biostatistics. 6th edition. Belmont, CA: Thomson/Brooks/Cole; 2006:615-616.

[23]. Cicchetti D. Guidelines, criteria, and rules of thumb for evaluating normed and standardized assessment instruments in psychology. Psychol Assess 1994; 6(4):284-290. [doi: 10.1037/1040-3590.6.4.284]

[24]. Armitage CJ, Conner M. Efficacy of the theory of planned behavior: A meta-analytic review. Br J SocPsychol 2001; 40: $471-99$.

[25]. Hardeman W, Johnston M, Johnston DW et al. Application of Theory of Planned Behavior in behavior change interventions: a systematic review. Psychol Health 2002; 17: 123-58.

[26]. Armitage C. Evidence that implementation intentions reduce dietary fat intake: a randomized trial. Health Psychol 2004; 23(3):31923.

[27]. Giles M, Connor S, McClenahan C, Mallett J, Stewart-Knox B, Wright M. Measuring young people's attitudes to breastfeeding using the Theory of Planned Behavior. Journal of Public Health 2007; 29(1): 17-26.

\section{Section 1}

\section{Supplementary File (Lifestyle Counseling Questionnaire)}

\section{Background questions}

NO

1. Gender: Male $\square$ or Female $\square$

2. Place of Employment/ practice:

3. Number of years qualified:

4. Area of specialty or clinical interest: Oncology $\square$ General practice $\square$ Other $\square$

5. Number of work days per week:

6. Do you provide lifestyle counseling to your patients diagnosed with cancer? Yes $\square$ No $\square$

\section{Section 2}

Each question in this section refers to PROVIDING LIFESTYLE COUNSELING on weight, diet and physical activity to your patients diagnosed with cancer during consultation 


\begin{tabular}{|c|c|c|c|c|c|c|c|c|c|c|}
\hline \multicolumn{11}{|c|}{ Attitude } \\
\hline 7. & $\begin{array}{l}\text { If I provide them lifestyle counseling, I will } \\
\text { feel that I am doing something positive for the } \\
\text { patient }\end{array}$ & Unlikely & 1 & 2 & 3 & 4 & 5 & 6 & 7 & Likely \\
\hline 8. & Doing something positive for the patient is & $\begin{array}{l}\text { Extremely } \\
\text { undesirable }\end{array}$ & - & $\overline{2}$ & - & 0 & 1 & 2 & 3 & Extremely desirable \\
\hline 9. & $\begin{array}{l}\text { If I provide them lifestyle counseling, it will } \\
\text { raise the patient's awareness on the benefits of } \\
\text { healthy lifestyle changes }\end{array}$ & Unlikely & 1 & 2 & 3 & 4 & 5 & 6 & 7 & Likely \\
\hline 10. & $\begin{array}{l}\text { Raising the patient's awareness on the benefits } \\
\text { of healthy lifestyle changes is }\end{array}$ & $\begin{array}{l}\text { Extremely } \\
\text { undesirable }\end{array}$ & - & $\overline{2}$ & - & 0 & 1 & 2 & 3 & Extremely desirable \\
\hline 11. & $\begin{array}{l}\text { If I provide lifestyle counseling, I will spend } \\
\text { more time for each consultation }\end{array}$ & Unlikely & 1 & 2 & 3 & 4 & 5 & 6 & 7 & Likely \\
\hline 12. & $\begin{array}{l}\text { Spending more time during each consultation } \\
\text { is }\end{array}$ & $\begin{array}{l}\text { Extremely } \\
\text { undesirable }\end{array}$ & - & $\overline{2}$ & $\overline{1}$ & 0 & 1 & 2 & 3 & Extremely desirable \\
\hline 13. & $\begin{array}{l}\text { I would rather focus on treating the patient's } \\
\text { presenting symptoms than providing lifestyle } \\
\text { counseling }\end{array}$ & $\begin{array}{l}\text { Strongly } \\
\text { disagree }\end{array}$ & 1 & 2 & 3 & 4 & 5 & 6 & 7 & Strongly agree \\
\hline 14. & $\begin{array}{l}\text { Focusing on treating the patient's presenting } \\
\text { symptoms than providing lifestyle counseling } \\
\text { is }\end{array}$ & $\begin{array}{l}\text { Extremely } \\
\text { undesirable }\end{array}$ & - & $\overline{2}$ & $\overline{-}$ & 0 & 1 & 2 & 3 & Extremely desirable \\
\hline 15. & $\begin{array}{l}\text { If I provide lifestyle counseling, I will sensitize } \\
\text { cancer patients to make better lifestyle choices }\end{array}$ & Unlikely & 1 & 2 & 3 & 4 & 5 & 6 & 7 & Likely \\
\hline 16. & $\begin{array}{l}\text { Sensitizing patients to make better lifestyle } \\
\text { choices is }\end{array}$ & $\begin{array}{l}\text { Extremely } \\
\text { undesirable }\end{array}$ & - & $\overline{2}$ & - & 0 & 1 & 2 & 3 & Extremely desirable \\
\hline 17. & $\begin{array}{l}\text { Providing lifestyle counseling to cancer } \\
\text { patients is }\end{array}$ & Harmful & 1 & 2 & 3 & 4 & 5 & 6 & 7 & Beneficial \\
\hline 18. & & $\begin{array}{l}\text { Good } \\
\text { practice }\end{array}$ & 1 & 2 & 3 & 4 & 5 & 6 & 7 & Bad practice \\
\hline \multicolumn{11}{|c|}{ Subjective Norms } \\
\hline 19. & Oncologists think I & Should not & - & - & $\overline{1}$ & 0 & 1 & 2 & 3 & $\begin{array}{l}\text { should provide lifestyle } \\
\text { counseling to cancer patients }\end{array}$ \\
\hline 20. & $\begin{array}{l}\text { What oncologists think I should do matters to } \\
\text { me }\end{array}$ & Not at all & 1 & 2 & 3 & 4 & 5 & 6 & 7 & Extremely \\
\hline 21. & My colleagues would & Disapprove & - & - & - & 0 & 1 & 2 & 3 & $\begin{array}{l}\text { Approve of my providing } \\
\text { lifestyle counseling to cancer } \\
\text { patients }\end{array}$ \\
\hline 22. & $\begin{array}{l}\text { My colleagues approval of my practice is } \\
\text { important to me }\end{array}$ & Not at all & 1 & 2 & 3 & 4 & 5 & 6 & 7 & Extremely \\
\hline 23. & Cancer patients would & Disapprove & - & $\overline{2}$ & $\overline{-}$ & 0 & 1 & 2 & 3 & $\begin{array}{l}\text { Approve of my providing } \\
\text { them lifestyle counseling }\end{array}$ \\
\hline 24. & $\begin{array}{l}\text { Patients approval of my practice is important } \\
\text { to me }\end{array}$ & Not at all & 1 & 2 & 3 & 4 & 5 & 6 & 7 & Extremely \\
\hline 25. & $\begin{array}{l}\text { The Medical and Dental Council (MDCN) } \\
\text { would }\end{array}$ & Disapprove & - & $\overline{2}$ & - & 0 & 1 & 2 & 3 & Approve \\
\hline 26. & $\begin{array}{l}\text { The MDCN's approval of my clinical practice } \\
\text { is important to me }\end{array}$ & Not at all & 1 & 2 & 3 & 4 & 5 & 6 & 7 & Extremely \\
\hline 27. & Other primary care doctors & Do not & - & - & - & 0 & 1 & 2 & 3 & $\begin{array}{l}\text { Do provide lifestyle } \\
\text { counseling to cancer patients }\end{array}$ \\
\hline 28. & $\begin{array}{l}\text { Doing what other primary care doctors do is } \\
\text { important to me }\end{array}$ & Not at all & 1 & 2 & 3 & 4 & 5 & 6 & 7 & Extremely \\
\hline 29. & $\begin{array}{l}\text { People who are important to me think I should } \\
\text { NOT provide lifestyle counseling to cancer } \\
\text { patients }\end{array}$ & $\begin{array}{l}\text { Strongly } \\
\text { disagree }\end{array}$ & 1 & 2 & 3 & 4 & 5 & 6 & 7 & Strongly agree \\
\hline 30. & $\begin{array}{l}\text { It is expected of me to provide lifestyle } \\
\text { counseling to cancer patients }\end{array}$ & $\begin{array}{l}\text { Strongly } \\
\text { disagree }\end{array}$ & 1 & 2 & 3 & 4 & 5 & 6 & 7 & Strongly agree \\
\hline \multicolumn{11}{|c|}{ Perceived behavioral control } \\
\hline 31. & $\begin{array}{l}\text { It takes a lot of time to provide lifestyle } \\
\text { counseling to cancer patients during } \\
\text { consultation }\end{array}$ & Unlikely & 1 & 2 & 3 & 4 & 5 & 6 & 7 & Likely \\
\hline 32. & $\begin{array}{l}\text { The time it takes to give lifestyle counseling } \\
\text { makes it }\end{array}$ & Less likely & - & $\overline{2}$ & $\overline{1}$ & 0 & 1 & 2 & 3 & $\begin{array}{l}\text { More likely I will provide } \\
\text { lifestyle counseling to cancer } \\
\text { patients }\end{array}$ \\
\hline 33. & $\begin{array}{l}\text { There are limited resources to support } \\
\text { providing lifestyle counseling to cancer } \\
\text { patients }\end{array}$ & Unlikely & 1 & 2 & 3 & 4 & 5 & 6 & 7 & Likely \\
\hline 34. & I am & Less likely & - & - & - & 0 & 1 & 2 & 3 & $\begin{array}{l}\text { More likely to provide } \\
\text { lifestyle counseling if there } \\
\text { are adequate support } \\
\text { resources }\end{array}$ \\
\hline 35. & $\begin{array}{l}\text { Oncologists are more suitably qualified to } \\
\text { provide lifestyle counseling to cancer patients }\end{array}$ & $\begin{array}{l}\text { Strongly } \\
\text { disagree }\end{array}$ & 1 & 2 & 3 & 4 & 5 & 6 & 7 & Strongly agree \\
\hline
\end{tabular}


Providing Lifestyle Counseling To Cancer Patients During Routine Consultation: Instrument....

36. I need more information on the benefits of lifestyle changes to counsel cancer patients about them

37. I have the expertise to provide lifestyle Strongly counseling to cancer patients

\section{Behavioral intention}

38. I intend to provide lifestyle counseling to my patients diagnosed with cancer during routine consultation

39. I expect to provide lifestyle counseling to my patients diagnosed with cancer during routine consultation

40. I want to provide lifestyle counseling to my patients diagnosed with cancer during routine Strongly disagree disagree

$\begin{array}{llllllll}1 & 2 & 3 & 4 & 5 & 6 & 7 & \text { Strongly agree }\end{array}$

Strongly disagree

$\begin{array}{llllllll}1 & 2 & 3 & 4 & 5 & 6 & 7 & \text { Strongly agree }\end{array}$

Strongly disagree

Strongly disagree

$\begin{array}{llllllll}1 & 2 & 3 & 4 & 5 & 6 & 7 & \text { Strongly agree }\end{array}$

$\begin{array}{llllllll}1 & 2 & 3 & 4 & 5 & 6 & 7 & \text { Strongly agree }\end{array}$

$\begin{array}{llllllll}1 & 2 & 3 & 4 & 5 & 6 & 7 & \text { Strongly agree }\end{array}$ consultation 